\title{
Stimulating effect of low-temperature plasma on seed germination characteristics of Trifolium repens
}

\author{
Nandintsetseg Munkhuu ${ }^{1, \mathrm{a}}$, Changyong Shao ${ }^{1, \mathrm{~b}}$, Decheng Wang ${ }^{1, \mathrm{c}}$, Liangdong Liu ${ }^{1, \mathrm{~d}}$, \\ Imtiaz Muhammad ${ }^{3, \mathrm{e}}$, Changbin He ${ }^{1, \mathrm{f}}$, Shanzhu Qian ${ }^{1,2, \mathrm{~g}}, \mathrm{Ru} \mathrm{Jia}^{1, \mathrm{~h}}, \mathrm{Jinkui}^{\prime}$ \\ Feng ${ }^{1, \mathrm{i}}$ \\ ${ }^{1}$ College of Engingeering, China Agricultural University, Beijing 100083, China; \\ ${ }^{2}$ College of Mechanical and Electrical Engineering, Inner Mongolia Agricultural University, \\ Hohhot 010018,China; \\ ${ }^{3}$ College of Agronomy and Biotechnology, China Agricultural University, Beijing 100093, \\ China; \\ àNandia_0011@yahoo.com, bshaochangyong68@163.com, ${ }^{\mathrm{c} w d c @ c a u . e d u . c n, ~}$ \\ d11d62336512@126.com, ${ }^{\mathrm{e}} \mathrm{mtz}$ yousafzai@yahoo.com, ${ }^{\mathrm{f}}$ changbin_he@126.com, \\ 9719725846@qq.com, ${ }^{\text {h}} 455084047 @ q q . c o m,{ }^{i}$ fengjinkui09@163.com
}

\begin{abstract}
The low temperature plasma (LTP) technology a new technology, uses for presowing treatments. In this research work we used the new LTP technology equipment "lowtemperature plasma modified instrument" and applied different doses in LTP technology to explore its effect on seed germination and other related characteristics on Trifolium repens crop seeds. The seed germination, germination vigor, plant fresh weight, plant dry weight, plant height and root length were significantly affected by LTP doses. The maximum seed germination $(73.75 \%$ ) recorded at LTP $120 \mathrm{~W}$ treatment followed by $72 \%$ at $160 \mathrm{~W}$. In addition early germination was observed on same treatment, while minimum seed germination was recorded at 140 Watts LTP treatment. Maximum plant height $(8.16 \mathrm{~mm})$ at $160 \mathrm{~W}$ and maximum root length $(74.14 \mathrm{~mm})$ was recorded at $180 \mathrm{~W}$ followed by root length $(73.89 \mathrm{~mm})$ at $160 \mathrm{~W}$. From our present work results, it is concluded that low temperature plasma dose $160 \mathrm{~W}$ is an optimum dose to get high germination rate and healthy seedlings of Trifolium repens crop seeds.
\end{abstract}

Keywords: Low-temperature plasma, trifolium repens, germination force, germination rate

\section{Introduction}

To secure uniform and early germination of seeds and to break seed dormancy, different methods of pre-sowing treatments have been developed to enhance germination rate of different plant species, mainly include, coat breaking, medicine, chemical mixing pile, medicament seed treatments and so on, used to enhance seed germination and seeds sterilization $^{[1,2]}$. They played an important role but still have many limitations, such as chemical processing method can't really improve seed itself to adapt to the environmental conditions, the overall disease resistance, cold resistance, early 
maturity, seed performance, causing the destruction of the soil environment. Along with the development of modern science and technology, represented by mechanical, electrical and thermal physics technology to deal with the method of seed research and application, starting to get use of crop seed with mechanical, electrical and thermal physical properties, by low temperature plasma treatment technology, magnetic treatment technology, biological spectrum technology, modern physics engineering technology such as solar irradiation technology processing crop seeds, the seeds can activate the endogenous substances, rejuvenate seeds, and stimulate and improve the seed itself ability to adapt to external environment, improve crops resistance, thus improve crop yield. At the same time reduce the risk of damage to the environment and pollution ${ }^{[3-7]}$. The low temperature plasma (LTP) technology is a new technology, which uses for pre-sowing treatments.

This research article is about the application of low temperature plasma technology to study, the effect of low temperature plasma treatments on seed germination and seedlings characteristics of Trifolium repens, its mechanism is by gas discharge, resulting from the gas ionization discharge, gas molecules and atoms are broken down and ionized. The negatively charged electrons and positively charged ions, uses for formation of plasma. When seeds by plasma glow are passed through discharge zone by light, the light interacts with seed surface layer, the light absorption and scattering occurs. Absorption of energy in form of light forced vibration and converts into heat energy. When material molecule absorbed photons, the electron will transitioned from a low energy state (ground) to a high energy (excited) state, molecular absorption of energy caused by the energy level transition, namely from the ground state transition to the excited level and cause the energy state transition of material, so that the seeds, enhance the vitality of life. A large number of experimental results show that low temperature plasma seed treatment technology has been in crop seed treatment before planting on significant results have been achieved. Through special equipment for processing, through germination experiment, pot experiment and field plot test, showed that the plasma activation seeds to produce a variety of biological effects, improved the germination potential, germination rate, root development, drought resistance and disease resistance ${ }^{[8]}$. The seedlings grow strong, improve quality, promote early maturity and also increase yield.

Low-temperature plasma seed treatment is a modern eco-agricultural technology that stimulates plant growth. It is based on non-ionizing low-level radiation, which can activate the vitality of seeds but without causing gene mutations, and is quite different from space breeding or mutation breeding by particle beam ${ }^{[8]}$. Zivkovic et al. reported that cold air plasma pretreatment significantly improved the germination of Paulownia tomentosa ${ }^{[\rho]}$ and Jiang JF also discovered that Low-temperature plasma seed treatment has been reported to improve the growth and yield of wheat ${ }^{[10]}$.

In the present work to test of data acquisition and intelligent monitoring system can realize the test conditions, test process and test results of key parameters, such as monitoring, control and acquisition ${ }^{[1]}$. For the development of digital processor intelligent seeds and development conditions, the results will guide the physical engineering seed processor output dose of key process parameters, such as maximizing the growth of the seed germination, improve the rejuvenation ability of seeds, at the same time for development, can be used for large-scale production of 
seed processor to provide technical support and application prospect, so the research is of great importance ${ }^{[12]}$.

\section{Materials and Methods}

\subsection{Experimental set-up}

Low temperature plasma seed treatment mechanism is low temperature plasma in the vacuum ultraviolet energy crop seeds of biological macromolecules of transition, the transition from the ground state to the excited state, which makes the seed produce positive biological effects. Non-ionizing radiation effect on organisms living tissue has been studied in recent years. The different non-ionizing radiation can produce different biological effects.

As the mechanism of low-temperature plasma effect on seeds is not very clear, and the LTP processing device is quite simple now (Figure 1), it becomes impossible to use this technology and devices in a large scale. However, this question also make low-temperature plasma treatment before seed sowing become into a very attractive project to explore, a large number of lab tests have been done in lab and small open field by the authors, all results prove that plants show better characteristics in terms of germination, root system, resistance to drought and diseases, early maturity and yield after their seeds well treated by a suitable dose of low-temperature plasma (LTP).

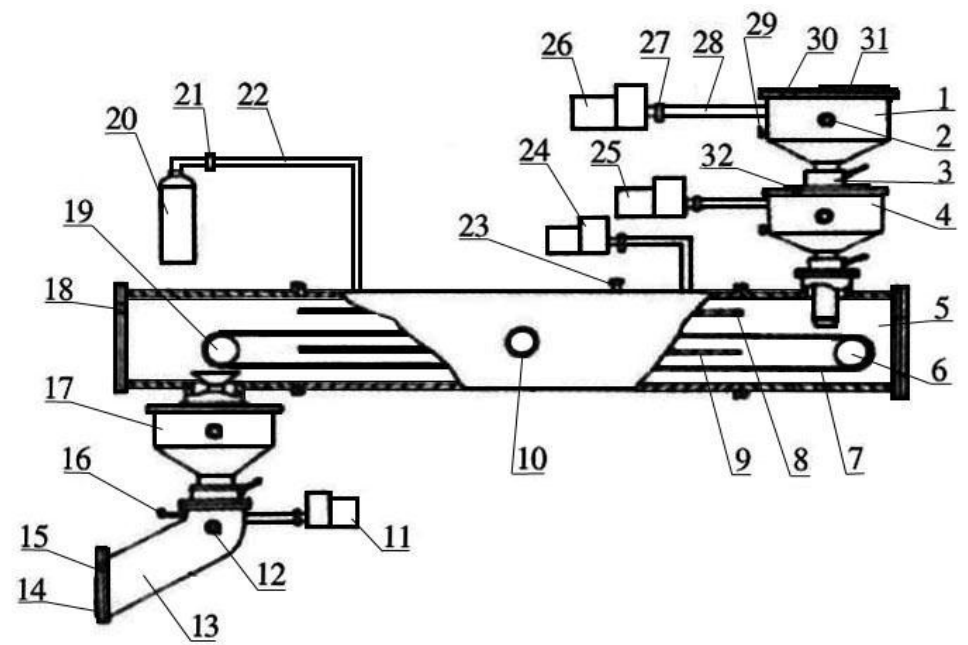

Fig.1 Diagram of low-temperature plasma test stand device

1, Feeder compartment I; 2, Detector tube I; 3, Butterfly gate; 4, Feeder compartment II; 5, Feeder compartment III; 6, Driven wheel; 7, Transmission belt; 8, Top crown; 9, Bottom crown; 10, Detector tube II; 11, Vacuum air pump I; 12, Detector tube III; 13, Feeder compartment IV; 14, Discharge port; 15, Thermocouple gauge tube I; 16, Deflating valve I; 17, Feeder 
compartment V; 18, Thermocouple gauge tube II; 19, Driver wheel; 20, Gas tank; 21, Gate; 22, Inlet pipe; 23, Deflating valve II; 24, Vacuum air pump II; 25, Vacuum air pump III; 26, Vacuum air pump IV; 27, Electromagnetic relief valve; 28, Vacuum tube; 29, Deflating valve III; 30, Thermocouple gauge tube III; 31, Feed cap; 32, Thermocouple gauge tube IV.

\subsection{Sample seeds}

Germination tests were carried out under laboratory conditions with Trifolium repens seeds purchased from the Royal Barenbrug Group.

\subsection{Experimental design}

\subsubsection{LTP treatment}

Using this technology the seeds of Trifolium repens were exposed to different treatments such as $0 \mathrm{~W}(1), 20 \mathrm{~W}(2), 40 \mathrm{~W}(3), 60 \mathrm{~W}(4), 80 \mathrm{~W}(5), 100 \mathrm{~W}(6), 120 \mathrm{~W}$ (7), 140W (8), 160W (9), 180W (10), 200W (11), 220W (12), 240W (13), 260W (14) and $280 \mathrm{~W}(15)$.

The experimental work was conducted in control conditions, 100 seeds were used for each treatment and the experiment was replicated four times. Data were recorded for the inspection of Trifolium repens seeds, referring to the corresponding test temperature and test time for testing. Seed germination and sprouting per day recorded, after the germination test shoot and root length, fresh weigh and dry weight were recorded.

2.3.2. Germination tests

Transparent Petri dish and moisture, to be cleaned and disinfected and make them non-toxic. Mat in one or more layers of filter paper in a petri dish, made it moist and drain off excess water. Take 100 completely worm disease-free seeds and placed in moist paper, covered the dish and gave treatment and then the germination was recorded daily and appropriate moisture content was maintained during the experimental period. The $20^{\circ} \mathrm{C}$ temperature was maintained during the experimental work.

\subsubsection{Dry weight}

The plants were first grown in $20^{\circ} \mathrm{C}$ and then plants were exposed to $105^{\circ} \mathrm{C}$ for 15 minutes and then to $60^{\circ} \mathrm{C}$ drying to constant weight.

\subsection{Statistical Analysis}

The data was analyzed by Microsoft office excel 2007 and statistix-8.1. As the experimental work conducted in controlled environmental conditions, so the statistical design CRD (completely randomized design) was used in the analysis. The LSD (least significant different) test was used for means comparison at $5 \%$ probability level.

\section{Results and Discussion}




\subsection{Germination}

The seeds of Trifolium repens were subjected to different low temperature plasma treatments to explore the effect of different low temperature plasma doses control, 20,40,60, 80, 100, 120, $140,160,180,200,220,240,260$ and $280 \mathrm{~W}$ on germination rate and force of Trifolium repens seeds.

Table 1. Germination rate of Trifolium repens seeds at different LTP treatments

\begin{tabular}{|c|c|c|c|c|c|c|c|c|c|c|c|c|c|c|c|}
\hline Treatment & $C K$ & $\begin{array}{l}20 \\
W\end{array}$ & $\begin{array}{l}40 \\
W\end{array}$ & $\begin{array}{l}60 \\
W\end{array}$ & $\begin{array}{l}80 \\
W\end{array}$ & $\begin{array}{l}100 \\
W\end{array}$ & $\begin{array}{l}120 \\
W\end{array}$ & $\begin{array}{l}140 \\
W\end{array}$ & $\begin{array}{l}160 \\
W\end{array}$ & $\begin{array}{l}180 \\
W\end{array}$ & $\begin{array}{l}200 \\
W\end{array}$ & $\begin{array}{l}220 \\
W\end{array}$ & $\begin{array}{l}240 \\
W\end{array}$ & $\begin{array}{l}260 \\
W\end{array}$ & $\begin{array}{l}280 \\
W\end{array}$ \\
\hline$\%$ Germination & $\begin{array}{r}66 . \\
5\end{array}$ & 67.75 & 68.75 & 69 & 66 & 69 & $73.75^{\mathrm{a}}$ & 64.5 & 72 & 66.75 & 70.25 & 69.25 & 64.75 & 71 & 72.25 \\
\hline$\%$ Increase & 0 & 1.25 & 2.25 & 2.5 & -0.5 & 2.5 & 7.25 & -2 & 5.5 & 0.25 & 3.75 & 2.75 & -1.75 & 4.5 & 5.75 \\
\hline $\begin{array}{l}\text { Relative to } \\
\text { CK (\%) }\end{array}$ & 0 & 1.88 & 3.38 & 3.76 & -0.8 & 3.76 & 10.90 & -3.01 & 8.27 & 0.38 & 5.64 & 4.14 & -2.63 & 6.77 & 8.65 \\
\hline
\end{tabular}

Table 2. Germination force of Trifolium repens seeds at different LTP treatments

\begin{tabular}{|c|c|c|c|c|c|c|c|c|c|c|c|c|c|c|c|}
\hline Treatment & $C K$ & $\begin{array}{l}20 \\
W\end{array}$ & $\begin{array}{l}40 \\
W\end{array}$ & $\begin{array}{l}60 \\
W\end{array}$ & $\begin{array}{l}80 \\
W\end{array}$ & $\begin{array}{l}100 \\
W\end{array}$ & $\begin{array}{l}120 \\
W\end{array}$ & $\begin{array}{l}140 \\
W\end{array}$ & $\begin{array}{l}160 \\
W\end{array}$ & $\begin{array}{l}180 \\
W\end{array}$ & $\begin{array}{l}200 \\
W\end{array}$ & $\begin{array}{l}220 \\
W\end{array}$ & $\begin{array}{l}240 \\
W\end{array}$ & $\begin{array}{l}260 \\
W\end{array}$ & $\begin{array}{l}280 \\
W\end{array}$ \\
\hline \%Vigor & 64 & 65 & 67.75 & 66.25 & 62.5 & 68 & $71.75^{\mathrm{a}}$ & 63 & 70.25 & 64 & 67.5 & 66.25 & 64 & 69 & 66.5 \\
\hline$\%$ Increase & 0 & 1 & 3.75 & 2.25 & -1.5 & 4 & 7.75 & -1 & 6.25 & 0 & 3.5 & 2.25 & 0 & 5 & 2.5 \\
\hline $\begin{array}{l}\text { Relative to } \\
\text { CK }(\%)\end{array}$ & 0 & 1.6 & 5.9 & 3.5 & -2.3 & 6.3 & 12.1 & -1.6 & 9.8 & 0.0 & 5.5 & 3.5 & 0.0 & 7.8 & 3.9 \\
\hline
\end{tabular}
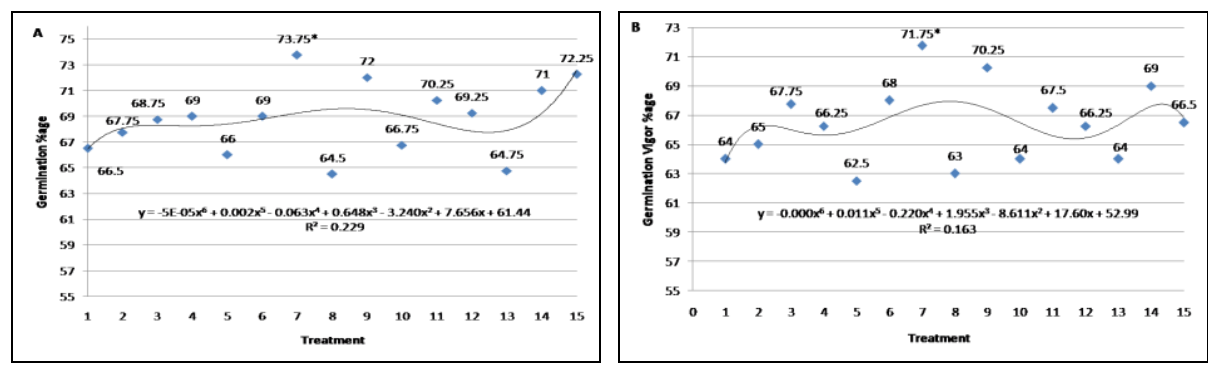

Fig.2 Effect of different low temperature plasma doses on germination rate (A) and germination force (B)

Note: *Optimum dose (Significantly high)

The germination rate $66.5 \%$ was recorded on control. With $20 \mathrm{~W}, 40 \mathrm{~W}$ and $60 \mathrm{~W}$ doses the germination rate non-significantly increased to $67.75,68.75$ and $69 \%$ respectively, then declined to $66 \%$ on $80 \mathrm{~W}$ and then increased to $69 \%$ with $100 \mathrm{~W}$ low temperature plasma treatment, then with further the germination rate significantly increased to $73.75 \%$ recorded at $120 \mathrm{~W}$, and then with further increase to $140 \mathrm{~W}$ the germination rate significantly declined to $64.5 \%$ and then again significantly increased to $72 \%$ with $160 \mathrm{~W}$ dose. Then $66.75,70.25,69.25,64.75,71$ and $72.25 \%$ germination rate was recorded for 180, 200, 220, 240, 260 and $280 \mathrm{~W}$ respectively (Table 1, Figure 2A).

The germination force was also significantly affected by LTP doses and almost similar trend was recorded as observed for the germination rate. The maximum 
germination force was recorded at $120 \mathrm{~W}$ which was $71.75 \%$ followed by $70.25 \%$ recorded at $160 \mathrm{~W}$ LTP treatment, while the lowest germination force was found at 80W LTP treatment (Table 2, Figure 2B).

\subsection{Plant height and Root length}

The data was recorded for Plant height and root in response to different doses control, 20, 40, 60, 80, 100, 120, 140, 160, 180, 200, 220, 240, 260 and $280 \mathrm{~W}$ of low temperature plasma. The LTP doses significantly affected the plant height as well as plant root length (Fig.3).
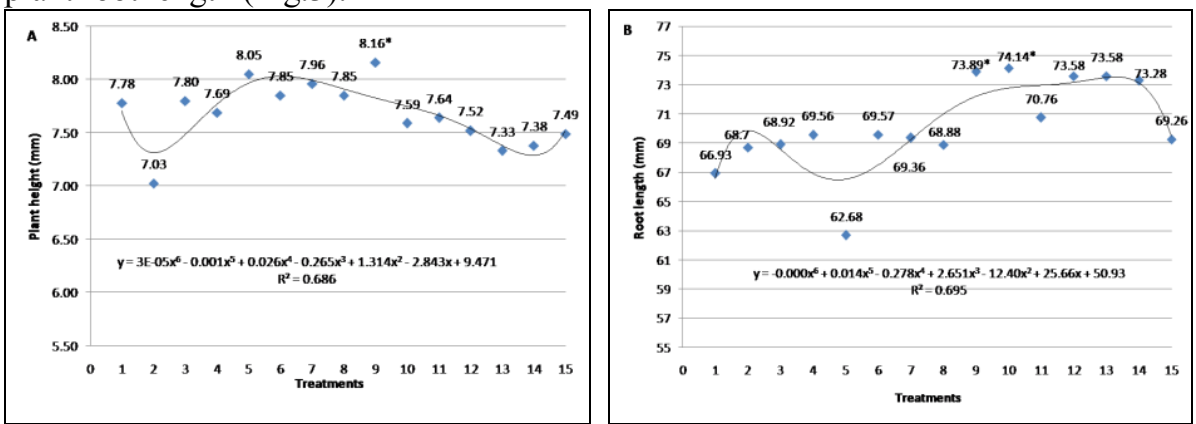

Fig.3 Effect of different low temperature plasma doses on plant height (A) and root length (B) Note: *Optimum dose (Significantly high)

The maximum plant height was recorded at $160 \mathrm{~W}$ treatment, which was $8.16 \mathrm{~mm}$, followed by $8.05 \mathrm{~mm}$ which was recorded at $80 \mathrm{~W}$ LTP treatment, while the minimum plant height $7.025 \mathrm{~mm}$ was recorded at 20W LTP treatment as shown in figure 3A.

On the other hand in case of roots the root length gradually enhanced from control to $60 \mathrm{~W}$ LTP treatment but then suddenly declined to $62.68 \mathrm{~mm}$ at $80 \mathrm{~W}$ LTP treatment. And then gradually increased to $73.89 \mathrm{~mm}$ at $160 \mathrm{~W}$ LTP treatment, and further improved to $74.14 \mathrm{~mm}$ at $180 \mathrm{~W}$ LTP treatment. While further increase to $200 \mathrm{~W}$ LTP treatment the root length declined to 70.76 and then increased to $73.58 \mathrm{~mm}$ at both220 and $240 \mathrm{~W}$ LTP treatments, then declined (Figure 3B).

\subsection{Plant fresh and dry weights}

The plants fresh weight as well as plants dry weight was recorded for the treated plants. The plant fresh weight enhanced with low temperature plasma treatments as given in Fig .4. 

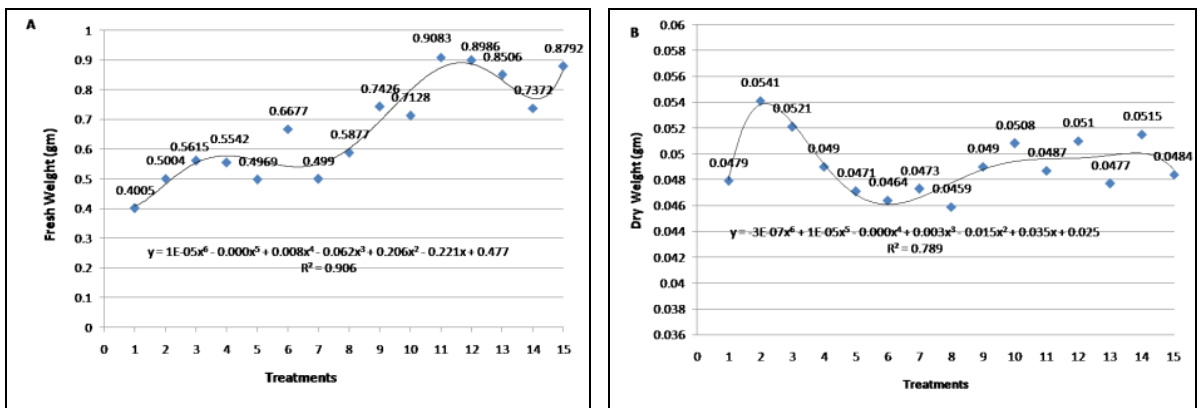

Fig.4 Effect of different low temperature plasma doses on plant fresh weight (A) and dry weight (B)

The maximum plant fresh weight $0.9083 \mathrm{~g}$ was recorded for the 200W LTP dose, followed by $0.8986 \mathrm{~g}$ and $0.8792 \mathrm{~g}$ at LTP doses $220 \mathrm{~W}$ and $280 \mathrm{~W}$ respectively, while minimum fresh weight $0.4005 \mathrm{~g}$ was recorded for the control plants, and $0.4969 \mathrm{~g}$ for the LTP dose 80W (Figure 4A).

On the other hand similarly minimum dry weight was recorded for the $140 \mathrm{~W}$ LTP dose, which was $0.0459 \mathrm{~g}$, while maximum plant dry weight was recorded at $20 \mathrm{~W}$, which was $0.0541 \mathrm{~g}$, followed by $0.0521 \mathrm{~g}$ and $0.0515 \mathrm{~g}$ at LTP doses $40 \mathrm{~W}$ and $260 \mathrm{~W}$ respectively as shown in Figure 4B.

\section{Conclusions}

In the present work we observed that LTP doses significantly affected Trifolium repens seed germination, germination vigor, plant height and root length. The maximum Trifolium repens seed germination percentage and germination vigor percentage were recorded at $120 \mathrm{~W}$ followed by $160 \mathrm{~W}$ LTP treatment, while maximum plant height and root length were recorded at 160W LTP dose.

\section{Acknowledgment}

This study is funded by China Agriculture Research System (CARS-35).

The study was supported by The ministry of Education basic business expenses special fund for scientific research projects, low temperature plasma treatment on the influence of seed germination seedling characteristics research 2013QJ019. 


\section{References}

1. Azad SM., Manik MR, Hassan MS and Matin MA. 2011. Effect of different pre-sowing treatments on seed germination percentage and growth performance of Acacia auriculiformis Journal of Forestry Research. Vol. 22( 2): 183-188

2. Dhoran V.S and Gudadhe S.P. (2012). Effect of Plant Growth Regulators on Seed Germination and Seedling Vigour in Asparagus sprengeri Regelin, International Research Journal of Biological Sciences, Vol. 1(7), 6-10

3. Decheng, W., Changyong, S., Xianfa, F., Dongxing, Z. (2013). Application Status and Development Trend of Low-temperature Plasma Equipment Used for Seed Treatment before Sowing. Agricultural Engineering, 2013, 3 (z1).

4. Min, W., Size, Y., Qingyun, C., Lihong, G., Guangliang, C., \& Xiujun, L. (2007). Effects of atmospheric pressure plasma on seed germination and seedling growth of cucumber. Transactions of the Chinese Society of Agricultural Engineering, 2007(2).

5. Yuhang, Z., Jinglou, Z., Qingfa, W. (2005). Physical methods used in the processing of sugar beet seeds. China Beet \& Sugar, (2):20-22.

6. Dubinov, A. E., Lazarenko, E. R., \& Selemir, V. D. (2000). Effect of glow discharge air plasma on grain crops seed. IEEE transactions on plasma science, 28(1), 180-183.

7. Lianglong, H., Lijia, T., Zhichao, H. (2007). Application of physical agriculture techniques in cleaned seeds treatments. Journal of Anhui Agricultural Science, 35(13):3778-3779.

8. Jiang J, Yufang Lu, Jiangang Li, Ling Li, Xin He, Hanliang Shao and Yuanhua Dong, 2014. Effect of Seed Treatment by Cold Plasma on the Resistance of Tomato to Ralstonia solanacearum (Bacterial Wilt), PLOS one Published: May 19, 2014 DOI: 10.1371/journal.pone.0097753

9. Zivkovic S, Puac N, Giba Z, Grubisic D, Petrovic ZL (2004) The stimulatory effect of non-equilibrium (low temperature) air plasma pretreatment on light-induced germination of Paulownia tomentosa seeds. Seed Sci Tecnol 32: 693-701.

10. Jiang JF, He X, Li L, Li JG, Shao HL, et al. (2014) Effect of cold plasma treatment on seed germination and growth of wheat. Plasma Sci Tech 16: 54-58. doi: 10.1088/1009$0630 / 16 / 1 / 12$

11. Changyong, S., Decheng, W., Xin, T., Lijing, Z., Yan, L. (2013). Stimulating effects of magnetized arc plasma of different intensities on the germination of old spinach seeds. Mathematical and Computer Modeling 58, 814-818.

12. Changyong, S., Xianfa, F., Xin, T., Lijing, Z., Lili, Z., Decheng, W. (2013). Effects of Low-temperature Plasma on Seed Germination Characteristics of Green Onion. Transactions of the Chinese Society for Agricultural Machinery. 6 (44): 201-205. 